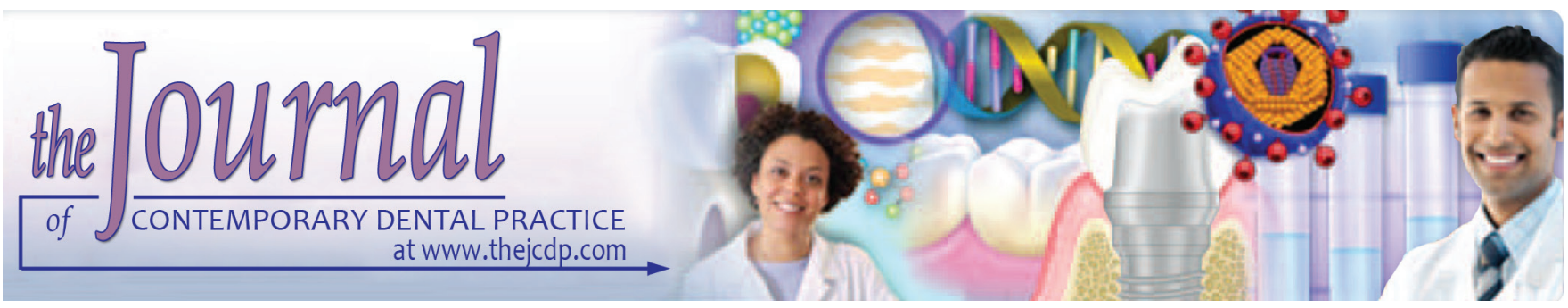

\title{
Child Abuse and Neglect: Do We know enough? A Cross- sectional Study of Knowledge, Attitude, and Behavior of Dentists regarding Child Abuse and Neglect in Pune, India
}

${ }^{1}$ Suruchi Malpani, ${ }^{2}$ Jatin Arora, ${ }^{3}$ Gunjeeta Diwaker, ${ }^{4}$ Priyajeet Kaur Kaleka, ${ }^{5}$ Aditi Parey, ${ }^{6}$ Parinita Bontala

\begin{abstract}
Introduction: Child abuse and neglect (CAN) is a significant global problem with a serious impact on the victims throughout their lives. Dentists have the unique opportunity to address this problem. However, reporting such cases has become a sensitive issue due to the uncertainty of the diagnosis. The authors are testing the knowledge of the dentists toward CAN and also trying to question the efforts of the educational institutions to improve this knowledge for the better future of the younger generation.
\end{abstract}

Materials and methods: Questionnaire data were distributed to 1,106 members regarding their knowledge, professional responsibilities, and behavior concerning child abuse.

Results: There were 762 responses to the questionnaire, yielding a response rate of $68.9 \%$. Although dentists consider themselves able to identify suspicious cases, only a small percentage of the participants correctly identified all signs of abuse and $76.8 \%$ knew the indicators of child abuse. Most of them were willing to get involved in detecting a case and about $90 \%$ believed that it is their ethical duty to report child abuse. Only $7.2 \%$ suspected an abuse case in the past. The numbers indicate a lack of awareness about CAN in these participants. No differences were observed between sexes, year of graduation,

\footnotetext{
${ }^{1,2}$ Department of Public Health, M.A. Rangoonwala College of Dental Sciences \& Research Centre, Pune, Maharashtra, India

${ }^{3}$ Department of Public Health Dentistry, University of Saskatchewan, Saskatoon, Canada

${ }^{4}$ Department of Pedodontics, J.N. Kapoor D.A.V. Centenary Dental College, Yamuna Nagar, Haryana, India

${ }^{5}$ Department of Health Science, California State University, Long Beach, California, USA

${ }^{6}$ Department of Pedodontics, St. Joseph Dental College, Eluru Andhra Pradesh, India

Corresponding Author: Jatin Arora, Department of Public Health, M.A. Rangoonwala College of Dental Sciences \& Research Centre, Pune, Maharashtra, India, Phone: +919224389700, e-mail: arorajatin004@gmail.com
}

types of license, frequency at which children were treated, and formal training already received.

Conclusion: A large proportion of child physical abuse cases go undocumented and unreported. The data showed that not all dental care providers and students were prepared to fulfill their legal and professional responsibilities in these situations.

Clinical significance: There should be modifications in the dental school curriculum focusing on educational experiences regarding child abuse to strengthen their capability to care and protect children.

Keywords: Abuse, Attitude, Child abuse, Child abuse and neglect, Child maltreatment, Dentist, Knowledge, Pune, India.

How to cite this article: Malpani S, Arora J, Diwaker G, Kaleka PK, Parey A, Bontala P. Child Abuse and Neglect: Do We know enough? A Cross-sectional Study of Knowledge, Attitude, and Behavior of Dentists regarding Child Abuse and Neglect in Pune, India. J Contemp Dent Pract 2017;18(2):162-169.

Source of support: Nil

Conflict of interest: None

\section{INTRODUCTION}

Child abuse and neglect (CAN) is a social and public health concern worldwide. It is a type of trauma that exerts a multitude of short- and long-term effects on children. ${ }^{1}$

Different terms, such as child abuse, child maltreatment, child infanticide which are hard to believe occur in all income, racial, religious, and ethnic groups even in the 21 st civilized century. ${ }^{2}$

Definitions of CAN vary due to different parenting behaviors in different cultures worldwide. Hence, some definitions focus on the behaviors or actions of adults while others consider abuse to take place if there is harm or the threat of harm to the child. ${ }^{3}$ The World Health Organization has defined "child abuse" as a violation of 
basic human rights of a child, constituting all forms of physical, emotional ill-treatment, sexual harm, neglect or negligent treatment, commercial or other exploitation, resulting in actual harm to child's health, survival, development, or dignity in the context of a relationship of responsibility, trust, or power. ${ }^{1}$

It is more difficult to define neglect when it comes to international standards of child protection. For example, co-sleeping is considered a norm in some countries and if the child is make to sleep alone in a separate room is perceived as neglectful whereas it is considered as modal way of caring for children in other countries. ${ }^{4}$

Neglect is a "type of maltreatment that refers to the failure by the caregiver to provide needed, age-appropriate care although financially able to do so or offered financial or other means to do so." ${ }^{\prime 5}$

Possible reason why children are the most vulnerable victims of neglect could be excessive dependence on their parents. ${ }^{6}$

Child neglect is hard to distinguish as it is a more subtle and nuanced form of abuse which leads to the deep "emotional scarring" of children. ${ }^{7}$ History of child abuse is very lengthy and dates back to ancient civilization with reports of infanticide, mutilation, abandonment, and other forms of violence against children. ${ }^{3}$ Child sacrifice is also documented in bible and archeological explorations have revealed jars of infant bones of biblical era. ${ }^{8}$

Child maltreatment was not mentioned in the literature until the 1873 sensational case of Mary Wilson drew a sharp line. In the early 1870s, there was no organization in existence to protect abused children. Ironically, the organization that came to her rescue was the American society for the prevention of cruelty to animals. This highly publicized case of child abuse led to the creation of the New York Society for the prevention of cruelty of children in $1874 .{ }^{7}$

Nevertheless, the issue did not receive widespread attention by medical profession until 1962 publication of physician Henry Kempe's landmark study of the medical records of hundreds of "battered children," which helped doctors not only in identifying child abuse and its effects but also to understand the need and awareness to report serious physical abuse to legal authorities. 3,9

The United States Department of Health and Human Services (2009) estimated that 794,000 children were found to have abused and neglected in 2007. ${ }^{10}$ The nation's capital, New Delhi has an over $83 \%$ of abuse rate and $69 \%$ of children are victims of abuse in India. ${ }^{11}$

Though CAN are significant problems worldwide but not as well documented. Dr David Finkelhor stated, “We don't know if this is being said as large proportion of child abuse cases go unreported or there aren't any published studies available." ${ }^{\prime 2}$
Especially among the Asian population, child abuse has been a topic often never discussed. ${ }^{13}$ In a survey done in 2011, in Bagalkot district of North Karnataka, 50\% of medical students admitted to not knowing the prevalence of CAN in India. ${ }^{14}$

Problem of child neglect is severe in India; the points below attest to this fact. ${ }^{14-16}$

- India is a country with the second largest population in the world, but birth registration is only $62 \%$.

- Every second child is underweight in India.

- In the world, every third child who is malnourished lives in India.

- Reduced learning capacity due to iodine deficiency in every second newborn.

- A total of $79 \%$ of children under 3 are anemic.

India has the world's largest labor trafficking problem.

An estimation of 1.2 million children are trafficked each year into exploitative work according to the International Labor Organization. ${ }^{17}$

During 2011, a total of 33,098 cases of sexual crimes against children were reported all across the nation as compared with 26,694 cases during 2010, suggesting a recent increase in $24 \% .{ }^{18}$ According to the latest statistics, in 2014, 172 cases of child sexual abuse were revealed by Pune Police between January and October compared with 126 cases recorded in 2013 in the same period, a steep rise of $35 \%{ }^{19}$

There can be several consequences as a result of abusive behavior toward the child. As a survivor of child abuse, there can be difficulties in the physical development of the child. A child can have many health-related issues, such as anxiety, depression, insomnia, and fear. Other effects could be lack of interest in social activities, difficulty in building healthy relationships at work and home. $^{20}$

Due to an alarming rise in child abuse cases, reporting is ethical and legal obligation of health care professionals. ${ }^{21}$ Most common signs of child abuse are in the orofacial region, hence, the dentists are in a unique position to detect the cases of child abuse. ${ }^{22}$ Lips are the most common site for inflicted injuries ( $54 \%$ ) followed by the oral mucosa, teeth, gingiva, and tongue. Such abuse cases are usually first witnessed by dentist. ${ }^{23-25}$

Furthermore, due to fear that the abuse will be recognized by the physician, abusive parents often do not take the child to the same physician but they tend to return to the same dentist. ${ }^{26}$ Moreover, physicians may not detect dental aspects of abuse or neglect as they receive minimal training in oral health..$^{25,27}$

Dental neglect, a form of physical neglect, is still a severe problem that hinders child development despite the great advancements in oral health. ${ }^{5}$ Dentists should make sure that the parents understand the explanation of the disease 
and its implications. ${ }^{28,29} \mathrm{Child}$ 's oral health if neglected due to lack of parental care may lead to dental caries. It is the most prevalent infectious disease in the children. ${ }^{30}$

Therefore, dentist and physicians should work in collaboration to prevent, detect, and treat CAN cases in the clinical setting. ${ }^{25}$

More than $70 \%$ of child abuse cases go unreported. ${ }^{11}$

Prevalence data from the web (newspaper report) reveal that in April 2015, police arrested doctor in Pune for not reporting even after treating a 2-year-old boy who was allegedly sodomized by 45 -year-old man. ${ }^{31}$

There are various reasons why dentists fail to report child abuse. Ignorance of the issue and a lack of awareness are the major barriers determined by 1986 survey. ${ }^{32,33}$ Other possible reason could be that dentists fear it will alienate their paying patients or fear retaliation lawsuits from the parents. ${ }^{26}$

Signs of abuse and neglect are best recognized by dentist who have been educated and five times more likely to make a report than the dentist who are not. ${ }^{33,34}$

Moreover, child maltreatment is a cyclic disease, so it should be prevented, identified, and reported with utmost urgency as ABUSED CHILDREN often become ABUSIVE PARENT. ${ }^{34}$ It has often been said that children who have been abused often grow up to abuse their own children, their spouse, and even their parents, a situation referred to as "RETRIBUTION ABUSE." 26

Despite the fact that Pune is the 9th most populous city in India and is home to over 100 educational institutes, however, no studies on the subject were identified after a thorough search of PubMed and Google scholar regarding dentists perception of their role in detecting and reporting suspected cases of CAN.

Considering the above-mentioned facts, the undermentioned study is stipulated to assess knowledge, attitude, and behavior of dentists in Pune regarding CAN to identify the barriers that prevent the reporting of suspicious cases.

\section{MATERIALS AND METHODS}

The study design was a descriptive cross-sectional study. The study was conducted from April to August 2016 after the official permission from the author of the Jeddah study. It had to be approved by our guide and also took written consent from the dean of our college to conduct the study in dental colleges across Pune. Considering dentist as a prime person in the detection of CAN, the study was conducted among staff members, postgraduate students, and interns across three dental colleges in Pune with the permission of respective principals. Totally, 1,106 participants were approached. The questionnaire consisted of 36 close-ended questions, which were modified from similar studies in the past. The data were collected in the form of paper surveys filled out by participants. All the data collected from the participants were manually entered into the Excel file.

The questions were divided into four sections and were built using multiple choice, true/false format. The first section acquired information about the professional background of the dentist. The second section was to test their knowledge about CAN. The third section was to understand their attitude toward CAN. The fourth section was to know their behavior in concern with CAN.

All the participants obtained a simplification of the study and were given a chance to clarify with their questions. The participation of the individual was completely voluntary and was informed that the study was independent of their academic grading.

During the data entry and analysis, a pilot study was conducted on 30 randomly selected participants. Data were manually entered in an Excel worksheet. Gross errors in the data were cleaned using Statistical Package for the Social Sciences (SPSS). The reliability of the questionnaire was confirmed using Cronbach's alpha. Data were analyzed using SPSS and Microsoft Excel. The results were presented as charts and tables.

\section{RESULTS}

\section{Demographic and Baseline Characteristics of Survey Participants}

A total of 1,106 students we approached (in-person) to complete the survey questionnaire and 773 completed it, resulting in a response rate of $69.89 \%$. Surveys which were $<10 \%$ complete were not entered and hence removed from the sample. The final sample size used for the analysis was 762. The demographic and baseline characteristics of the respondents have been summarized in Table 1 .

Table 1: Demographics and baseline characteristics among respondents

\begin{tabular}{llll}
\hline & \multicolumn{3}{c}{$n=762$} \\
\cline { 2 - 4 } Variable & Median & Maximum & Minimum \\
\hline Age & 26 years & 57 & 21 \\
Year of graduation & 2014 & 2017 & 1979 \\
$\begin{array}{l}\text { Variable } \\
\text { Gender }\end{array}$ & Frequency $(\mathrm{n})$ & Percentage \\
$\quad$ Female & & & \\
$\quad$ Male & 494 & 64.8 & \\
$\begin{array}{l}\text { Educational institution } \\
\quad \text { Government }\end{array}$ & 268 & 35.2 & \\
$\quad$ & 123 & & \\
$\quad$ Private & 639 & 16.1 & \\
Highest scientific & & 83.9 & \\
$\quad$ BDS & & & \\
$\quad$ MDS & 44 & 5.8 & \\
Postgraduate student & 176 & 23.1 & \\
Intern & 284 & 37.3 & \\
\hline
\end{tabular}




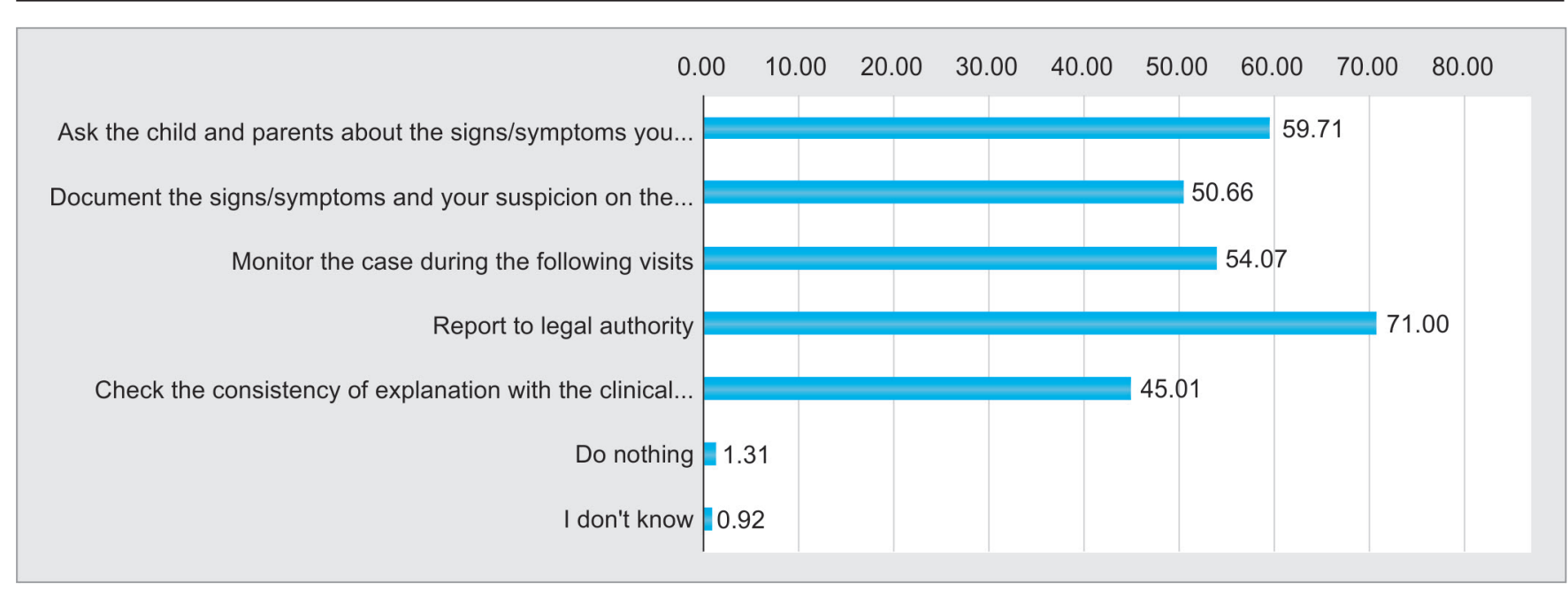

Graph 1: Participants' answer for first action to be taken if child abuse is suspected

\section{Child Abuse and Neglect Literacy, Training, and Reporting}

Self-reported CAN literacy in survey participants was as follows: $4.1 \%$ reported receiving a formal training about child physical abuse. Of those who did receive formal training did so in undergraduate (35\%) and postgraduate programs (61\%).

Nearly $90.3 \%$ agreed that it is a dentist's legal responsibility to report CAN. On being asked about the course of action if a case of child abuse is suspected, the response varied significantly (Graph 1). The authority to which child abuse should be reported were as follows: Ministry of Health $-4.9 \%$, Social Agency - 17.3\%, CHILDLINE $21.7 \%$, and police $-47.5 \%$. Participants were then asked about circumstances in which they would report child abuse (Graph 2).

\section{Assessment of Knowledge of CAN among Respondents}

The survey questionnaire consisted of various sections that evaluated dentist's knowledge of the signs and symptoms of physical abuse and dentist's course of action if a case of CAN is suspected: 81.6, 85.2, and 75.6\% respectively, identified bite marks, delay in seeking medical attention, and repeated injury to dentition as signs of child abuse.

In one such question, eight out of the nine signs listed were correct, and the participants were asked to identify all signs indicating CAN. Only $0.7 \%$ of the participants correctly identified all signs. There was no significant difference in knowledge of participants who reported having received formal training and those who did not.

Approximately $84.8 \%$ of the participants correctly identified the gender mostly affected by CAN (female) and $65.9 \%$ correctly identified the type of family group where CAN is more likely (extended vs nuclear).

Participants were also asked at what age child abuse is most likely and the results have been summarized in Graph 3.

Nearly $76.8 \%$ correctly identified the indicators of child abuse.

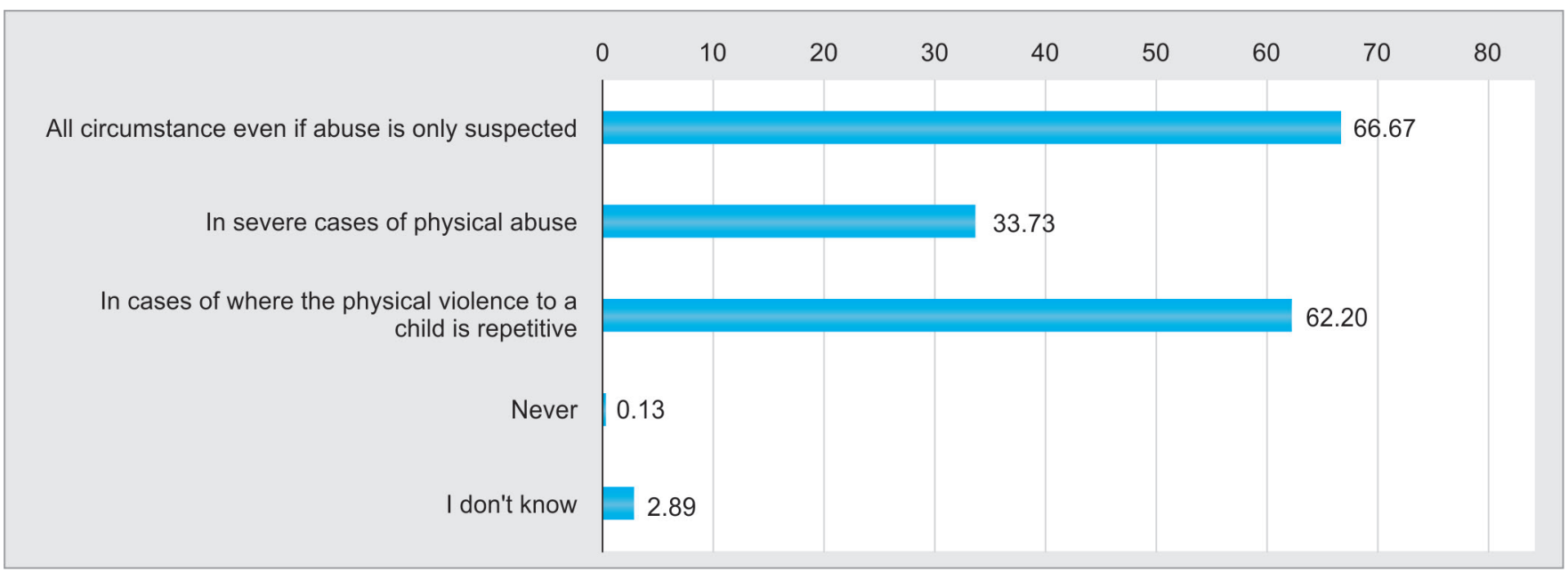

Graph 2: Participants' answer for circumstance in which they would report child abuse 


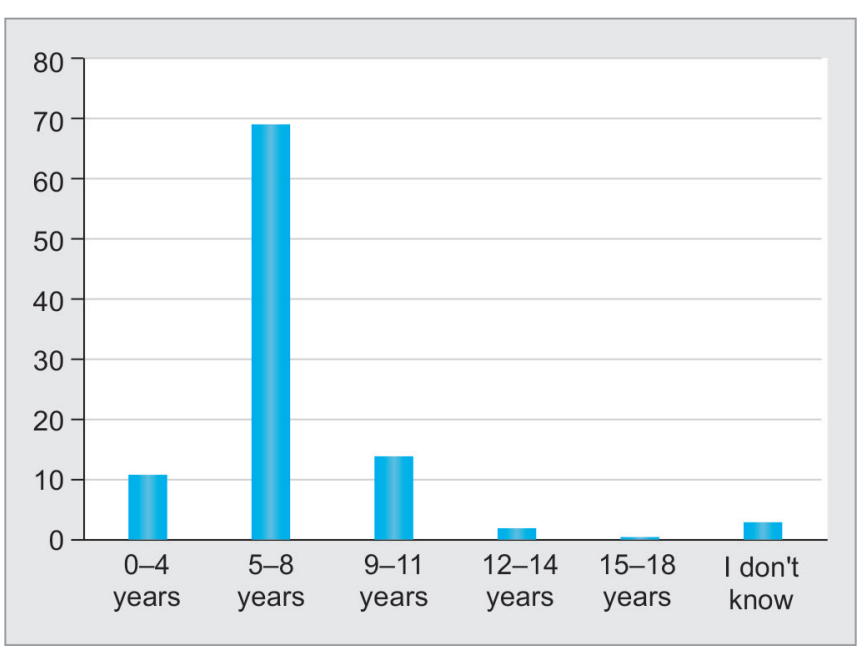

Graph 3: Participants' perception of age group most affected by CAN

\section{Attitude of Respondents toward CAN}

To assess the attitude of survey participants toward child abuse, a series of objective questions were asked to which participants responded as shown in Table 2.

\section{Survey Participants' Past Experiences with CAN}

A total of $95.3 \%$ respondents said they would be willing to get involved in detecting a case of child abuse and $7.2 \%(n=55)$ said they have suspected a case of physical abuse in the past. Participants' responses on how they dealt with the situation varied significantly.

\section{DISCUSSION}

The term "protection" ideally should mean protection from all forms of violence, abuse, and exploitation. This underlines the significance of anticipating and preventing potential damage to a child, with the primary requirement of identification of a problem. The Indian Child Abuse, Neglect, and Child Labor group and Indian Medical Association (IMA) has stalwartly promulgated the view that "protection" not only includes protection from disease, poor nutrition, and lack of knowledge but also action against abuse and exploitation. ${ }^{1}$

In 2011, 9th International Society for the Prevention of CAN Asia Pacific Conference of CAN resulted in the "Delhi Declaration." The Delhi Declaration attested to urgent need undertake productive measures against CAN and build a safe and thriving community for every child. Medical professionals are required by law to report cases of child sexual abuse, under the "The Protection of Children from Sexual Offences Act, 2012." However, the Indian Academy of Pediatrics and IMA admits that hardly any training is provided to medical students, practicing doctors, dentists, or any allied medical health professionals on the subject of child abuse. ${ }^{1}$ Out of 762 participants, 477 strongly agreed that providing child physical abuse training at the workplace is necessary.

It can be inferred from this finding that there is a serious need to incorporate trainings for child safety in dentistry education. Efforts should be made by the Dental Council of India (DCI) to introduce management of CAN in the dental curriculum at the level of undergraduation as well as post-graduation. There should be mandatory seminars to spread awareness regarding CAN among dental educators as well as practicing dentists and their staff.

It can be concluded from the results that students and dentists understand that they have a responsibility toward reporting suspected CAN cases since around

Table 2: Attitude of respondents toward CAN

\begin{tabular}{|c|c|c|c|c|c|}
\hline & Strongly agree $n(\%)$ & Agree $n(\%)$ & Neutral n (\%) & Disagree $n(\%)$ & $\begin{array}{l}\text { Strongly } \\
\text { disagreen (\%) }\end{array}$ \\
\hline $\begin{array}{l}\text { Detecting and reporting childhood physical } \\
\text { abuse is important }\end{array}$ & $647(84.9)$ & $111(14.6)$ & $2(0.3)$ & $0(0.0)$ & $2(0.3)$ \\
\hline $\begin{array}{l}\text { Dentists have an important role in detecting } \\
\text { and reporting child physical abuse cases } \\
\text { against children }\end{array}$ & $250(32.8)$ & $480(63.0)$ & $26(3.4)$ & $6(0.8)$ & $0(0.0)$ \\
\hline $\begin{array}{l}\text { As a dentist, you are confident to detect child } \\
\text { physical abuse cases }\end{array}$ & $55(7.2)$ & $211(27.7)$ & $235(30.8)$ & $256(33.6)$ & $5(0.7)$ \\
\hline $\begin{array}{l}\text { Documenting the signs/symptoms of abuse in } \\
\text { the patient file is important }\end{array}$ & 304 (39.9) & $424(55.6)$ & $24(3.1)$ & $9(1.2)$ & $1(0.1)$ \\
\hline $\begin{array}{l}\text { Documenting the signs/symptoms of abuse in } \\
\text { the patient file is important }\end{array}$ & $253(33.2)$ & $427(56.0)$ & $80(10.5)$ & $2(0.3)$ & $0(0.0)$ \\
\hline $\begin{array}{l}\text { Reporting physical abuse cases to a legal } \\
\text { authority is important }\end{array}$ & $420(55.1)$ & $298(39.1)$ & $39(5.1)$ & $2(0.3)$ & $3(0.4)$ \\
\hline $\begin{array}{l}\text { The amount of materials presented about the } \\
\text { topic of physical child abuse at your dental } \\
\text { school is sufficient }\end{array}$ & $39(5.1)$ & $78(10.2)$ & $206(27.0)$ & $411(53.9$ & $28(3.7)$ \\
\hline $\begin{array}{l}\text { Providing child physical abuse training in the } \\
\text { work place is important }\end{array}$ & $477(62.6)$ & $237(31.1)$ & $31(4.1)$ & $17(2.2)$ & $0(0.0)$ \\
\hline
\end{tabular}


$90 \%$ participants agreed that it is dentists' responsibility to report CAN. Out of the 762 participants, 647 participants strongly agreed that detecting and reporting childhood physical abuse is important, and 250 respondents strongly agreed that dentists have an important role in detecting and reporting child abuse cases. They agreed that the documentation of signs and symptoms of abuse is important and reporting it to the legal authorities is equally essential.

However, the barrier in reporting is a lack of awareness about the course of action for handling the CAN cases. ${ }^{35}$ Even after understanding the importance of reporting the child abuse cases, participants had reservations in reporting it due to the fear of losing patient's trust, ill treatment from patient's guardians, doubtful about the diagnosis of CAN, lack of knowledge regarding management, and tackling of CAN.

Child abuse can be a verbal abuse which can cause emotional trauma to a child or physical abuse, sexual abuse, or exploitation. As per the response from the participants in our survey, many of them were able to identify the type of physical abuse. The majority of respondent correctly identified bite marks, delay in seeking medical attention, and repeated injuries to dentition as signs of child abuse, indicating that participating dentists had some knowledge about detecting physical signs of child abuse. Although very few dentists were able to identify them all correctly which reinforces the need for education surrounding this subject. ${ }^{36}$

Most common type of injuries include head, neck, and face regions; hence, the dentists are in a unique position to identify and report these cases. ${ }^{22}$ Therefore, it is extremely important for dental and medical professionals to be equipped with the information needed to determine whether injury is accidental in nature or as a result of abusive behavior toward the child. When suspecting a case of CAN, a proper documentation and investigation should be done by the guardian's assessment. Parents should be interrogated in a nonthreatening way and should be asked about the cause of the physical injury or abnormal behavior of the child. Sometimes lack of proper resources and the absence of innate parenting skills could also be the reason for child neglect. ${ }^{36}$

Malnourishment is also one of the signs of child neglect. Efforts should be made by the dental staff to assess the appropriate reason for it by talking to the caretakers of a child, whether it is due to neglect and carelessness or due to inefficiency in providing nourishment to the child due to financial reasons. ${ }^{36}$ If it is due to lack of finances, parents should be informed about the NGO like save the children India, etc. It has launched a campaign "Nutrition for Babies" to improve and spread awareness in the society about nutritional health for children. Furthermore, several Nutrition Rehabilitation Centers have been established by government's health department to treat cases of severe acute malnutrition in some states of India. ${ }^{37}$

When asked to the participants about whom to report the child abuse cases, majority of them answered to report it to the police followed by CHILDLINE, Social Agency, and Ministry of Health respectively. On being asked about what actions the participants will take if they suspect a case of CAN, around $67 \%$ participants answered they will report to the legal authorities even if the abuse is only suspected. Around $62 \%$ of participants stated that they will report CAN only in cases if the physical violence on a child is repetitive. Hence, it can be derived that there is still lack of information among the dental professionals regarding the right authority to report CAN cases.

The survey results imply that the vulnerable age for child abuse is 5 to 8 and female child is more susceptible than the male child. Low socioeconomic background, large families, and lack of money are also causes of delay or absence in seeking medical care for the child, which can be attributed to the child neglect. As per Integrated Child Protection Scheme, child safety is about keeping children safe from any dangers and risks to their lives during childhood. Although CHILDLINE, India is playing an important role in dealing with CAN cases, more strict laws should be made by the government against CAN.

Stress should be given to educate kids at schools, and by their family members about appropriate or inappropriate touch on their body. Efforts should be made by parents and school teachers to be friendly with children so that if they ever become victim of physical abuse, they do not hesitate sharing about it with their family members or school teachers.

This study has identified that there is a definite need to address the subject of ignorance in future dental practitioners regarding CAN. The DCI should consider potential inclusion of CAN literacy in the curriculum of pediatric dentistry. To address the issue of awareness among practicing dentists, one potential solution may be organizing workshops regarding CAN in collaboration with NGOs that are actively working for the cause. These workshops can be organized at the periodic American Dental Association meetings that are commonplace in most Indian cities and may have associated continuing dental education points as a motivation for practicing dentists to attend it.

There is scope of further research on the subject in other areas of the country. Also a follow-up longitudinal study can be done on the same population group after organizing workshops to educate the target population about CAN. 


\section{ACKNOWLEDGMENTS}

Authors would like to thank Dr Renuka Nagrale (Department Head of Public Health Dentistry, M.A. Rangoonwala College of Dental Sciences \& Research Centre, Pune, Maharashtra, India), Dr Shrikant Murlidharan (Department of Public Health Dentistry, M.A. Rangoonwala College of Dental Sciences \& Research Centre, Pune, Maharashtra, India), Dr Dinraj Kulkarni (Oral and Maxillofacial Pathology and Microbiology, M.A. Rangoonwala College of Dental Sciences \& Research Centre, Pune, Maharashtra, India) for their great efforts and guidance during study. Warm regards to Dr Meaad A. Mogaddam (Faculty of Medicine, King Abdulaziz University, Jeddah, Kingdom of Saudi Arabia) for his great support in building the questionnaire.

\section{REFERENCES}

1. Saini N. Child abuse and neglect in India: time to act. Jpn Med Assoc J 2013 Sep-Oct;56(5):302-309.

2. Hinchliffe J. Forensic odontology, part 5. Child abuse issues. Br Dent J 2011 May;210(9):423-428.

3. Zwi AB, Krug EG, Mercy JA, Dahlberg LL. World report on violence and health - exploring Australian responses. Aust N Z J Public Health 2002 Oct;26(5):405-408.

4. Lansford JE, Godwin J, Uribe Tirado LM, Zelli A, Al-Hassan SM, Bacchini D, Bombi AS, Bornstein MH, Chang L, DeaterDeckard K, et al. Individual, family, and culture level contributions to child physical abuse and neglect: a longitudinal study in nine countries. Dev Psychopathol 2015 Nov;27(4 Pt 2): 1417-1428.

5. Lourenço CB, Saintrain MV, Vieira AP. Child, neglect and oral health. BMC Pediatr 2013 Nov;13(1):188.

6. Iravani MR. Child abuse in India. Asian Soc Sci 2011 Mar;7(3):150-153.

7. Aileen M. Reluctant to report: the mandated reporting practices of child care providers [Dissertations]. Paper 437; 2011.

8. Zigler E, Hall NW. Physical child abuse in America: past, present, and future. Child maltreatment: theory and research on the causes and consequences of child abuse and neglect. Vol. 30. New York: Cambridge University Press; 1989. p. 38-75.

9. Crane J. "The bones tell a story the child is too young or too frightened to tell": the Battered Child Syndrome in Post-war Britain and America. Soc Hist Med 2015 Nov;28(4):767-788.

10. Sousa C, Herrenkohl TI, Moylan CA, Tajima EA, Klika JB, Herrenkohl RC, Russo MJ. Longitudinal study on the effects of child abuse and children's exposure to domestic violence, parent-child attachments, and antisocial behavior in adolescence. J Interpers Violence 2011 Jan;26(1):111-136.

11. Gupta N, Aggarwal N. Child abuse. Delhi Psy J 2012;15(2): 416-419.

12. WHO Switzerland, Crimes against children research center United States of America. Promoting research to prevent child maltreatment. Conference Material; Report (Summary); 2013. p. 1-13.

13. Nalini PR, Thirunavukarasu MR, Dongre AR. Reports of child abuse in India from scientific journals and newspapers: an exploratory study. Online J Health Allied Sci 2013 Oct-Dec;12(4):8.
14. Kirankumar SV, Noorani H, Shivprakash PK, Sinha S. Medical professional perception, attitude, knowledge, and experience about child abuse and neglect in Bagalkot district of north Karnataka: a survey report. J Indian Soc Pedod Prev Dent 2011 Oct;29(3):193-197.

15. Mehta N. Child Protection and Juvenile Justice System. Mumbai: CHILDLINE India Foundation; 2008.

16. Acharya T, Malonia A, Pathak R, Sodani V, Ganesh M, Bhaskar V. Child abuse: our role! J Ahmedabad Dent Coll Hosp (JADCH) 2014 Sep;5(2):63-67.

17. Ghosh B. Trafficking in women and children in India: nature, dimensions and strategies for prevention. Int J Hum Rights 2009 Dec;13(5):716-738.

18. Behere PB, Sathyanarayana Rao TS, Mulmule AN. Sexual abuse in women with special reference to children: Barriers, boundaries and beyond. Indian J Psychiatry 2013 Oct;55(4):316-319.

19. Times of India. Sharp rise in child sexual abuse cases. Newspaper on the Internet [cited 2014 Nov 18]. Available from: http:/ / www.googleweblight.com/?lite_url=http:/ / www.m.timesofindia.com/city/pune/sharp-rise-inchild-sexual-abuse-cases / articleshow / 45183423. cms\&ei $=$ dcnh0_2u\&lc $=e n-i n \& s=1 \& m=157 \&$ host $=w w w$. google.co.in\&ts=1472797941\&sig=akovd64gmkwbzfvwzipe 4whdigyr9us-lw.

20. Kemoli AM, Mavindu M. Child abuse: a classic case report with literature review. Contemp Clin Dent 2014 Apr-Jun;5(2):256-259.

21. Garrocho-Rangel A, Márquez-Preciado R, Olguín-Vivar AI, Ruiz-Rodríguez S, Pozos-Guillén A. Dentist attitudes and responsibilities concerning child sexual abuse. A review and a case report. J Clin Exp Dent 2015 Jul;7(3):e428-e434.

22. Deshpande A, Macwan C, Poonacha KS, Bargale S, Dhillon S, Porwal P. Knowledge and attitude in regards to physical child abuse amongst medical and dental residents of central Gujarat: a cross-sectional survey. J Indian Soc Pedod Prev Dent 2015 Jul-Sep;33(3):177-182.

23. Puri H, Kadam S, Umarji HR. Domestic violence in childrenwhat lies behind the door?. Santosh Univ J Health Sci 2015;1(1):41-44.

24. Rai S, Kaur M, Kaur S. Dental perspective: recognition and response to child abuse and neglect in Indian setting. J Indian Acad Oral Med Radiol 2011 Jan-Mar;23(1):57-60.

25. Lough P. Mandated reporting of child abuse: answers for dentists. J Calif Dent Assoc 2004 Apr;32(4):307-312.

26. Mouden LD. The dental team's role in identifying and preventing family violence. American Dental Assistants Association; 2013. p. 1-19.

27. Kellogg N, American Academy of Pediatrics Committee on Child Abuse and Neglect. Oral and dental aspects of child abuse and neglect. Pediatrics 2005 Dec;116(6):1565-1568.

28. American Academy of Pediatrics Committee on Child Abuse and Neglect, American Academy of Pediatric Dentistry, American Academy of Pediatric Dentistry Council on Clinical Affairs. Guideline on oral and dental aspects of child abuse and neglect. Pediatr Dent 2008-2009;30(Suppl 7):86-89.

29. Stavrianos C, Stavrianou D, Stavrianou I, Kafas P. Nutritional child neglect: a review. IJFS Internet J Forensic Sci 2009;4(1): 1-7.

30. Ramazani N. Child dental neglect: a short review. Int J High Risk Behav Addict 2014 Dec;3(4):1-62. 
31. Times of India. Doctor arrested for failing to report child abuse case. Newspaper on the Internet [cited 2015 Apr 02]. Available from: http://www.googleweblight.com/?lite_url=http:/ / m.timesofindia.com/city / pune/doctor-arrested-for-failing-to-report-child-abusecase / articleshow / 46776418.cms\&ei $=1 \mathrm{ktdc} 8 \mathrm{~m} 6 \& \mathrm{lc}=\mathrm{en}-$ in\&s $=1 \& m=157 \&$ host $=w w w . g o o g l e . c o . i n \& t s=1472797623 \&$ sig=akovd67dp3_t2w_ymnyd-kynzno6cneb6a.

32. Pushpalatha C, Tammannavar PS, Nimbal A, Jain S. Is dental neglect a child abuse? A review. Int J Adv Res 2013;1(5): 273-275.

33. Tsang A, Sweet D. Detecting child abuse and neglect - are dentists doing enough? J Can Dent Assoc 1999 Jul-Aug;65(7): 387-391.
34. Malhotra S, Gupta V, Alam A. Child abuse and neglect: role of dentist in detection and reporting. J Educ Ethics Dent 2013 Jan;3(1):2-5.

35. Al-Dabaan R, Newton JT, Asimakopoulou K. Knowledge, attitudes, and experience of dentists living in Saudi Arabia toward child abuse and neglect. Saudi Dent J 2014 Jul;26(3):79-87.

36. Farley R, Reece R. Recognizing when a child's injury or illness is caused by abuse. Washington, DC: US Department of Justice, Office of Juvenile Justice and Delinquency Prevention; 2006. p. 1-24.

37. Save the Children India. Fighting Malnutrition through Nutrition Rehabilitation Centres; 2013. Available from: https:/ / www.savethechildren.in/news/fighting-malnutrition. 